\title{
WP 59_13
}

\author{
Theophilos Papadimitriou
}

Democritus University of Thrace, Greece

\author{
Periklis Gogas
}

Democritus University of Thrace, Greece

The Rimini Centre for Economic Analysis (RCEA), Italy

Vasilios Plakandaras

Democritus University of Thrace, Greece

\section{FORECASTING THE NOK/USD EXCHANGE RATE WITH MACHINE LEARNING TECHNIQUES}

Copyright belongs to the author. Small sections of the text, not exceeding three paragraphs, can be used provided proper acknowledgement is given.

The Rimini Centre for Economic Analysis (RCEA) was established in March 2007. RCEA is a private, nonprofit organization dedicated to independent research in Applied and Theoretical Economics and related fields. RCEA organizes seminars and workshops, sponsors a general interest journal The Review of Economic Analysis, and organizes a biennial conference: The Rimini Conference in Economics and Finance (RCEF) . The RCEA has a Canadian branch: The Rimini Centre for Economic Analysis in Canada (RCEACanada). Scientific work contributed by the RCEA Scholars is published in the RCEA Working Papers and Professional Report series.

The views expressed in this paper are those of the authors. No responsibility for them should be attributed to the Rimini Centre for Economic Analysis. 


\title{
Forecasting the NOK/USD Exchange Rate with Machine Learning Techniques
}

\author{
Theophilos Papadimitriou ${ }^{1}$, Periklis Gogas ${ }^{*}$ and Vasilios Plakandaras ${ }^{+}$ \\ Department of Economics \\ Democritus University of Thrace, Greece, University Campus Komotini,
}

\begin{abstract}
In this paper, we approximate the empirical findings of Papadamou and Markopoulos (2012) on the NOK/USD exchange rate under a Machine Learning (ML) framework. By applying Support Vector Regression (SVR) on a general monetary exchange rate model and a Dynamic Evolving Neuro-Fuzzy Inference System (DENFIS) to extract model structure, we test for the validity of popular monetary exchange rate models. We reach to mixed results since the coefficient sign of interest rate differential is in favor only with the model proposed by Bilson (1978), while the inflation rate differential coefficient sign is approximated by the model of Frankel (1979). By adopting various inflation expectation estimates, our SVR model fits actual data with a small Mean Absolute Percentage Error when an autoregressive approach excluding energy prices is adopted for inflation expectation. Overall, our empirical findings conclude that for a small open petroleum producing country such as Norway, fundamentals possess significant forecasting ability when used in exchange rate forecasting.
\end{abstract}

Key words: International Financial Markets, Foreign Exchange, Support Vector Regression, Monetary exchange rate models.

JEL Code: G15, F30, F31

\section{Introduction}

The reported causal relationship between exchange rate evolution and monetary policy (Rime et al, 2010) led economists and policy makers to propose a significant number of monetary exchange rate models in order to explain exchange rate behavior and describe the linkage between exchange rate fluctuations and fundamentals. Nevertheless, the empirical findings of Cheung et al (2005) on various currencies reject the intertemporal and universal applicability of a specific monetary exchange rate model on all exchange rates. The disparities between members of the EMU is an example of political and social factors that obscure the actual impact of monetary policy on exchange rate evolution and thus impend proper modeling of macroeconomic variables influence on exchange rates.

\footnotetext{
${ }^{1}$ Corresponding author, papadimi@ierd.duth.gr

*pgkogkas@ierd.duth.gr

+vplakand@ierd.duth.gr
} 
Under these impediments on model selection, Norway is a prominent candidate to examine the aforementioned relationship. With a national currency among the ten most traded currencies (BIS, 2010) while being an economy with constant budget surpluses without a substantial external debt, Norway is a small open economy that does not participate in international political and economic organizations. Another interesting factor is the existence of a sovereign wealth fund (presently known as Government Pension Fund) with a present worth approximately $\$ 783.3$ billion USD, which accumulates the income from oil exports in order to provide funding to future generations. Another key role of the Fund is to absorb the effects of oil price surges on domestic demand. As a result, we expect that the fundamentals of the Norwegian economy are more isolated to exogenous shocks than in other developed economies. Thus, modeling the Norwegian Krone/United States Dollar (NOK/USD) exchange rate may be an excellent example to observe the impact of monetary policy on exchange rates.

A recent addition to the existing literature is the paper of Papadamou and Markopoulos (2012). The authors apply Johansen and Juselius (1990) cointegration tests and Vector Error Correction Models (VECM) on a monetary exchange rate model of general form in order to verify the potential validity of four popular monetary exchange rate models proposed in literature. With the use of various inflation expectation approximations they forecast the exchange rate one quarter ahead. The empirical results of their paper are a) the empirical validation of the forecasting power of monetary exchange rate models without identification of a specific model version and b) on a short term horizon almost half of the exchange rate variability can be attributed to oil price fluctuations.

In this paper we approach the problem investigated by Papadamou and Markopoulos in 2012, under a machine learning perspective. We build a forecasting model for the NOK/USD exchange rate using the Support Vector Regression (SVR) methodology. Following the suggestions of the aforementioned paper, we also examine different inflation expectation measures, in order to discern the potential value of each inflation approximation in exchange rate evolution. On a second stage, since an SVR model does not provide an analytical model structure, we apply the Dynamic Evolving Neuro-Fuzzy Inference System (DENFIS) on the forecasted values of the SVR model, in order to extract the effect of each macroeconomic variable fluctuation to the exchange rate determination.

\section{Literature review}

Soon after the breakdown of the Bretton Woods fixed exchange rate system, a significant number of monetary exchange rate models were proposed, that established a linkage of exchange rate evolution to fundamentals. In this paper we examine the four most influential theoretic approaches. The flexible price monetary model of Frenkel (1976) has been for many years the workhorse for exchange rate economics. It suggests a positive and proportionally equal relationship between exchange rate and money supply, while it implies a negative relationship between exchange rate and domestic 
GDP level. On the other hand, inflation rate differential is supposed to have a negative impact on a country's exchange rate, with a rise to the former leading to an appreciation of the latter. Bilson (1978) builds on the aforementioned framework, suggesting that a rise in domestic interest rate leads to an exchange rate depreciation, dropping the inflationary part.

On a different path, the sticky-price model of Dornbuch (1978) claims that all prices are sticky and thus constant (determined on the short-run by the Phillips augmented expectations curve), accepts perfect capital mobility and monetary policy is the driver of exchange rate evolution. Resulting to different conclusions from the flexible price model, he argues that an interest rate increase in domestic rate will produce an exchange rate appreciation, but his model also lacks an inflationary perspective. Finally, the interest rate differential model of Frankel (1979) combines inflationary perspectives with the model proposed by Dornbuch, claiming that a rise in domestic inflation will lead to exchange rate depreciation.

Ever since the proposition of the aforementioned theoretical models, there has been an extensive research in validating empirically their applicability, mainly since a potential validity can be extremely useful in monetary policy determination. Chinn (2007a) develops a model on Malaysian Ringgit and the United States Dollar, whose coefficients support Bilson's suggestions, extending (2007b) his empirical results to the Phillipines Peso/ United States Dollar. Miyakoshi (2000) reaches on similar findings for the Korean Won/German Mark and Korean Won/Japanese Yen. Evidence in favor of Bilson's monetary exchange rate model can be found in the work of Cushman (2007) on the Canadian Dollar/ United States Dollar (CAD/USD) and Loria et al (2009) on the Mexican Peso/ United States Dollar (MXN/USD). On a similar research framework, Frenkel and Koske (2004) test monetary exchange rate models on various currencies traded with euro. They conclude that the inferred model structure is different for every single rate, but overall macroeconomic variables possess forecasting potential.

Under a portfolio perspective, Adhyankar, Sarno and Valente (2005) measure higher returns in investing portfolios that use monetary models for determining the mixture of their components than portfolios based on random selection. Recently, Della Corte and Tsiakas (2011) extend the research to dynamic portfolios changing ratios over time for nine currencies. Selection of the portfolio according to the evolution of basic macroeconomic variables achieves higher and more sustainable returns over all other alternative approaches they include in their research framework. Overall, Engel and West (2005) show that on the long run, there is sustainable evidence in using monetary exchange rate models for forecasting the behavior of foreign exchange markets.

\section{Machine Learning Techniques}

\subsection{Support Vector Regression (SVR)}

The Support Vector Regression is a direct extension of the classic Support Vector Machine algorithm that has exhibited its ability in forecasting exchange rates (see Ince 
and Trafalis; 2005, Brandl et al, 2009). The algorithm proposed by Vladimir Vapnik (1992) originates from the field of statistical learning. When it comes to regression, the basic idea is to find a function that has at most a predetermined deviation from the actual values of the actual dataset. In other words we do not care about the error of each forecast as long as it doesn't violate the threshold, but we will penalize a higher deviation. The Support Vector (SV) set which bounds this "error-tolerance band" is located in the dataset through a minimization procedure.

One of the main advantages of the SVR in comparison to other machine learning techniques is that, in perfect conditions, it yields a minimization problem with unique global minimum point, avoiding local minima. The model is built in two steps: the training and the testing step. In the training step, the largest part of the dataset is used for the estimation of the function (i.e. the detection of the Support Vectors that define the band); in the testing step, the generalization ability of the model is evaluated by checking the model's performance in the small subset that was left aside during training.

Using mathematical notation and starting from a training dataset $D=\left[\left(\boldsymbol{x}_{1}, y_{1}\right),\left(\boldsymbol{x}_{2}, y_{2}\right), \ldots\left(\boldsymbol{x}_{n}, y_{n}\right)\right], \boldsymbol{x}_{i} \in \mathbb{R}^{m}, y_{i} \in \mathbb{R}, i=1,2, \ldots . n$, where for each observation pair, $\boldsymbol{x}_{i}$ are the observation samples and $y_{i}$ is the dependent variable (the target of the regression system) the linear regression function takes the form of $f(x)=$ $\boldsymbol{w}^{T} \boldsymbol{x}+b$. The SVR methodology tries to reach two contradictory goals: a) find a solution that best approximates the given dataset (i.e. a large part of the datapoints should be inside the tolerance "belt", while a few points will lie out of bounds) and b) to find a solution that generalizes to the underlying population. This is achieved by solving:

$$
\begin{array}{r}
\min \left(\frac{1}{2}\|\boldsymbol{w}\|^{2}+C \sum_{\iota=1}^{n}\left(\zeta_{i}+\zeta_{i}^{*}\right)\right) \\
\text { subject to }\left\{\begin{array}{c}
y_{i}-\left(\boldsymbol{w} \boldsymbol{x}_{i}+b\right) \leq \varepsilon+\zeta_{i} \\
\left(\boldsymbol{w} \boldsymbol{x}_{i}+b\right)-y_{i} \leq \varepsilon+\zeta_{i}^{*} \\
\zeta_{i}, \zeta_{i}^{*} \geq 0
\end{array}\right.
\end{array}
$$

where $\varepsilon$ defines the tolerance belt around the regression, and $\zeta_{i}, \zeta_{i}^{*}$ are slack variables controlled through a penalty parameter $C$ (see Figure 1 ). All the points inside the tolerance belt have $\zeta_{i}, \zeta_{i}^{*}=0$. The problem (1) is a convex quadratic optimization problem with linear constraints and has a unique solution. The first part of the objective function controls the generalization ability of the regression, by imposing the smaller possible $\|\boldsymbol{w}\|$. This is not an obvious statement and a detailed analysis of the SVR minimization process is not in the scope of this paper, however we can hint that the smaller is $\|\boldsymbol{w}\|$, the closer to parallel to the $\mathbf{x}$-axes is the regression function. Geometrically we can see that a parallel line to the $\mathbf{x}$-axes, maximizes the covered area by the tolerance belt, which means maximum generalization ability. The second part of the objective function controls the regression approximation to the training data points (by increasing $\mathrm{C}$ we penalize with a bigger weight any point outside the tolerance belt 
i.e. with $\zeta_{i} \geq 0$ or $\zeta_{i}^{*} \geq 0$ ). The key element in the SVR concept is to find the balance between the two parts in the objective function, controlled by the $\varepsilon$ and $\mathrm{C}$ parameters.

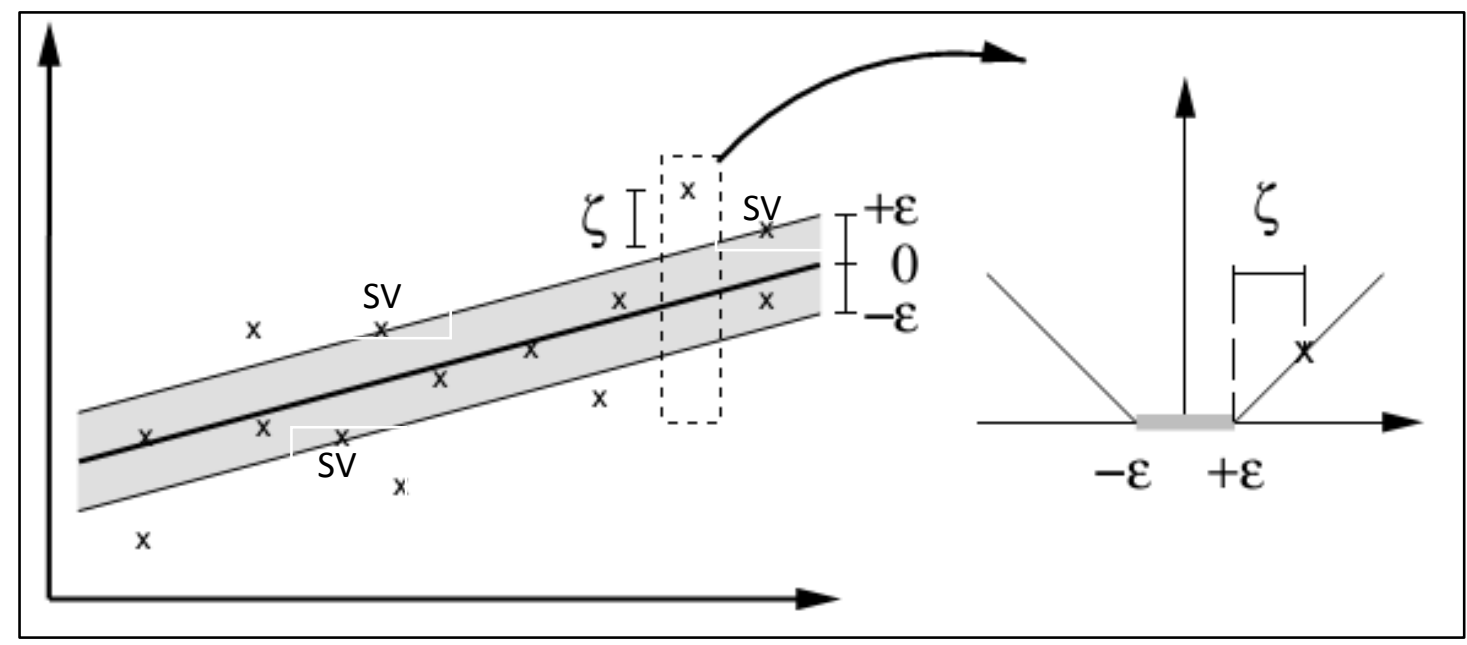

Figure 1: Upper and lower threshold on error tolerance indicated with letter $\varepsilon$. The boundaries of the error tolerance band are defined by Support Vectors (SVs). On the right we see the projection form 2 to 3 dimensions space and the projected error tolerance band. Forecasted values greater than $\varepsilon$ get a penalty $\zeta$ according to their distance from the tolerance accepted band (source Scholckopf and Smola, 2002).

Using the Lagrange multipliers from the system (1) we achieve the objective function:

$$
\begin{aligned}
& L:=\frac{1}{2}\|\boldsymbol{w}\|^{2}+C \sum_{i=1}^{n}\left(\zeta_{i}+\zeta_{i}^{*}\right)-\sum_{i=1}^{n}\left(\eta_{i} \zeta_{i}+\eta_{i}^{*} \zeta_{i}^{*}\right)-\sum_{i=1}^{n} a_{i}\left(\varepsilon+\zeta_{i}-y_{i}+\boldsymbol{w}^{T} \boldsymbol{x}_{i}+\right. \\
& b)-\sum_{i=1}^{n} a_{i}^{*}\left(\varepsilon+\zeta_{i}^{*}+y_{i}-\boldsymbol{w}^{T} \boldsymbol{x}_{i}-b\right)
\end{aligned}
$$

where $\eta_{i}, \eta_{i}^{*} a_{j}, a_{j}^{*}$ are the Lagrange multipliers. The dual problem can be formed as:

$$
\begin{gathered}
\max \left(-\frac{1}{2} \sum_{i, j=1}\left(a_{i}-a_{i}^{*}\right)\left(a_{j}-a_{i}^{*}\right) \boldsymbol{x}_{i}^{T} \boldsymbol{x}_{j}-\varepsilon \sum_{i=1}^{n}\left(a_{i}-a_{i}^{*}\right)+\sum_{i=1}^{n} y_{i}\left(a_{i}-a_{i}^{*}\right)\right) \\
\text { subject to }\left\{\begin{array}{c}
\sum_{\mathrm{i}=1}^{\mathrm{n}}\left(\alpha_{\mathrm{i}}-\alpha_{\mathrm{i}}^{*}\right)=0 \quad \mathrm{i}=1, \ldots, \mathrm{n} \\
\alpha_{\mathrm{i}}, \alpha_{\mathrm{i}}^{*} \in[0, \mathrm{C}]
\end{array}\right.
\end{gathered}
$$

and the solution is given by:

and

$$
\begin{gathered}
\boldsymbol{w}=\sum_{i=1}^{n}\left(a_{i}-a_{i}^{*}\right) \boldsymbol{x}_{i} \\
y=\sum_{i=1}^{n}\left(a_{i}-a_{i}^{*}\right) \boldsymbol{x}_{i}^{T} \boldsymbol{x}
\end{gathered}
$$

Real life phenomena are rarely described correctly by linear regression; they are too complex for such a simplistic approximation. A natural intuition to treat real phenomena datasets would be to project them into a higher dimensional space where the transformed dataset can be described by a linear function. The "kernel trick" follows the projection idea while ensuring minimum computational cost: the dataset is mapped in an inner 
product space, where the projection is performed using only dot products within the original space through special "kernel" functions, instead of explicitly computing the mapping of each data point. Non-linear kernel functions have evolved the SVR mechanism to a non-linear regression model, able of approximating non-linear phenomena.

In our simulations we tested four kernels: the linear, the radial basis function (RBF), the sigmoid and the polynomial. The mathematical representation of each kernel is:

Linear

$$
K_{1}\left(x_{1}, x_{2}\right)=x_{1}^{T} x_{2}
$$

$\mathrm{RBF}$

$$
K_{2}\left(\boldsymbol{x}_{1}, \boldsymbol{x}_{2}\right)=e^{-\gamma\left\|x_{1}-x_{2}\right\|^{2}}
$$

Polynomial

$$
K_{3}\left(\boldsymbol{x}_{1}, \boldsymbol{x}_{2}\right)=\left(\gamma \boldsymbol{x}_{1}^{T} \boldsymbol{x}_{2}+r\right)^{d}
$$

Sigmoid (MLP)

$$
K_{4}\left(\boldsymbol{x}_{1}, \boldsymbol{x}_{2}\right)=\tanh \left(\gamma \boldsymbol{x}_{1}^{T} \boldsymbol{x}_{2}+r\right)
$$

with factors $d, r, \gamma$ representing kernel parameters.

\section{The Data and Methodology}

\subsection{The Data}

For the empirical part of our study we use data for Norway and the U.S. for money supply (M2), overnight interest rate, real GDP, five different expected inflation rate approximations and real oil prices ${ }^{2}$. All data variables are sampled quarterly spanning from 1997Q1 to 2008Q2. Apart from the interest rates and inflation expectations, all data variables are expressed as natural logarithms of their original values.

\subsection{The Empirical Model}

According to Engel and West (2005), macroeconomic variables appear to have a significant ability in forecasting exchange rates in the long run. We apply the Support Vector Regression methodology on a general form monetary model, which takes into account the differences in macroeconomic fundamentals between the U.S. and Norway:

$$
\begin{aligned}
s_{t+1} & =c_{o}+\beta_{1} s_{t}+\beta_{2}\left(m_{t}-m_{t}^{*}\right)+\beta_{3}\left(y_{t}-y_{t}^{*}\right)+\beta_{4}\left(r_{t}-r_{t}^{*}\right)+\beta_{5}\left(\pi_{t}-\pi_{t}^{*}\right) \\
& +\beta_{6} \text { oilp }_{t}+\beta_{7} T+e_{t}
\end{aligned}
$$

where $s$ is the nominal NOK/USD exchange rate, $c_{o}$ is a constant, T is the time trend, $m$ is the money supply (M2), $y$ is the real GDP, $r$ is the nominal interest rate, oilp is the oil price adjusted for the Norwegian CPI and $\pi$ is the expected domestic inflation rate. The asterisk denotes the foreign economy variables.

\footnotetext{
${ }^{2}$ The oil prices are an index, which has 2005 as base year and it is the arithmetic mean of the spot prices of Brent, West Texas Intermediate and Dubai Fateh. Moreover, oil prices are calculated in Norwegian Kroner dividing by the consumer price index in Norway.
} 


\subsection{Expected Inflation Approximations}

For the time series of the expected inflation rates for both countries we use five different approximations. A common way in the relevant literature to estimate inflation expectations is by following the autoregressive trend of the phenomenon. Thus, by using a rolling window on the past four quarters' growth in consumer prices we proxy inflation rate expectations based on an $\mathrm{AR}(4)$ model. Moreover, extending the above framework, we apply an $\operatorname{ARMA}(\mathrm{p}, \mathrm{q})$ model fitted on past inflation changes. The lag structure of the ARMA model is determined by the Schwartz (1978) Information Criterion.

In accordance to economic theory and the empirical findings of De Grauwe (1996), oil exporting countries are supposed to experience exchange rate changes in line with oil price fluctuations (i.e. when oil prices rise the exchange rate appreciates and vice versa). In order to observe the exogenous effect of oil price on exchange rate, we use two CPI's excluding energy prices of the above $\operatorname{AR}(4)$ and $\operatorname{ARMA}(p, q)$ inflation models. In this way, we distinguish inflation evolution from oil price fluctuations and thus the effects of oil prices on the NOK/USD rate are expected to be direct and noticeable.

Moreover, Svensson (1994) proposes that forward rates can be used as a proxy to inflation expectations. Kloster (2000) argues that the forward rate plays a crucial role on Norges's Bank Inflation Report. In other words differences between the Norwegian and U.S. dollar forward rates may be interpreted as differences in the inflation rate expectations between these two economies. So, the long-term forward rate differential may imply inflation differential. In order to incorporate this perspective, inflation expectations are also measured with the one year forward rate starting two years ahead, using the two year and three year swap rate for Norway and the U.S. The inflation approximations used are summarized in Table 1.

Table 1: Inflation Expectation Approximations

\begin{tabular}{|c|c|}
\hline $\begin{array}{l}\text { Model } \\
\text { Name }\end{array}$ & Approximation \\
\hline Model 1 & Inflation expectations proxied by the preceding four quarters' growth in CPI \\
\hline Model 2 & Inflation expectations proxied by the preceding four quarters growth in CPI (less energy) \\
\hline Model 3 & $\begin{array}{l}\text { Inflation expectations proxied by CPI inflation forecasts from an ARMA }(1,1) \text { model for } \\
\text { Norway and an ARMA }(2,2) \text { model for the U.S. }\end{array}$ \\
\hline Model 4 & $\begin{array}{l}\text { Inflation expectations proxied by CPI-less energy inflation forecasts from ARMA }(2,2) \\
\text { models for both countries }\end{array}$ \\
\hline Model 5 & Inflation expectations proxied by 1 year forward rate 2 years ahead \\
\hline
\end{tabular}

According to Table 1, we estimate five alternative SVR models corresponding to each inflation expectation model. Each of the SVR models is trained using the four selected kernels discussed above resulting in twenty alternative empirical models. We measure the one-period-ahead forecasting accuracy of each model by the Mean Absolute Percentage Error (MAPE). The relevant formula is: 


$$
M A P E=\frac{1}{n} \sum_{i=1}^{n}\left|\frac{\hat{y}_{i}-y_{i}}{y_{i}}\right|
$$

where $\widehat{y}_{l}$ is the forecasted exchange rate for period $i, y_{i}$ is the actual value and $n$ is the total number of the observations used.

\section{Empirical Findings}

We approximate inflation expectations with five different models and test the forecasting efficiency for each of the four kernels. The parameters of the best model for each kernel case are selected through an exhaustive search procedure, training $6.4 * 10^{7}$ models in total. All SVRs are used for one-quarter-ahead forecasting, in order to detect the optimum model/kernel combination that best forecasts the behavior of the NOK/USD exchange rate, as measured by MAPE criterion.

In their study, Papadamou and Markopoulos (2012) apply cointegration tests using a Johansen maximum likelihood multivariate cointegration test. All time series are found to be $\mathrm{I}(1)$ in the levels, $\mathrm{I}(0)$ in first differences, one cointegrating vector is detected and 5 VECM models on first differences are constructed: one for each inflation model. The optimum lag structure for the VAR model is one, based on the Schwartz (1978) Information Criterion. Then unrestricted VECMs are used for forecasting. The empirical results of our best trained models and the ones from Papadamou and Markopoulos (2012) are reported in Table 2.

\section{Table 2: Comparison of Empirical Results}

\begin{tabular}{|c|c|c|c|}
\hline Inflation Expectation & Kernel & \multicolumn{2}{|c|}{ MAPE(\%) } \\
\hline & & $\mathrm{ML}$ & VECM \\
\hline \multirow{4}{*}{ Model 1} & Linear & 1.511 & \multirow{4}{*}{1.06} \\
\hline & $\mathrm{RBF}$ & 0.595 & \\
\hline & Sigmoid & 1.311 & \\
\hline & Polynomial & 1.249 & \\
\hline \multirow{4}{*}{ Model 2} & Linear & 1.488 & \multirow{4}{*}{0.98} \\
\hline & $\mathbf{R B F}$ & 0.149 & \\
\hline & Sigmoid & 1.383 & \\
\hline & Polynomial & 0.921 & \\
\hline \multirow{4}{*}{ Model 3} & Linear & 1.427 & \multirow{4}{*}{1.09} \\
\hline & $\mathrm{RBF}$ & 0.358 & \\
\hline & Sigmoid & 1.801 & \\
\hline & Polynomial & 1.177 & \\
\hline \multirow{4}{*}{ Model 4} & Linear & 1.353 & \multirow{4}{*}{1.03} \\
\hline & $\mathrm{RBF}$ & 1.106 & \\
\hline & Sigmoid & 1.453 & \\
\hline & Polynomial & 1.183 & \\
\hline \multirow{2}{*}{ Model 5* } & Linear & 1.505 & \multirow{2}{*}{$0.84^{*}$} \\
\hline & $\mathrm{RBF}$ & 1.278 & \\
\hline
\end{tabular}




\begin{tabular}{cc}
\hline Sigmoid & 1.407 \\
Polynomial & 1.263 \\
\hline \hline Note: Best values are marked in bold for Machine Learning and with an asterisk for the
\end{tabular}
Note: Best values are marked in bold for Machine Learning and with an asterisk for the VECM.

Comparing the results from the two methodologies presented in Table 3, we observe that the best overall fit as it is measured by the forecasting criterion is achieved with an SVR model employing the RBF kernel and Model 2 specification for the expected inflation rate. The corresponding MAPE value is 0.149 while the best VECM model is the one using Model 5's specification for the expected exchange rate with MAPE value 0.84 respectively. The results show that the best VECM model produces more than five times higher forecasting error (0.84) than the SVR one (0.149). In Figure 2 we present the forecasted series of the best kernel SVR and VECM models along with the actual NOK/USD exchange rate time series for each inflation specification model.

The SVR model with the best fit on NOK/USD exchange rate is the one with the AR(4) CPI-less energy inflation rate expectation (Model 2). Thus, when we exclude the exogenous effect of oil price fluctuations from the inflation differential (as these are determined internationally and not domestically in Norway) the future evolution of the exchange rate using fundamentals is forecasted more accurately than all other inflation rate models. This finding is rather interesting suggesting that a significant part of the forecasting error between Models 1 and 2 can be attributed to the effect of oil prices on inflation expectations. In other words, the construction of a price index relieved of oil price effect as an inflation rate proxy attributes significant forecasting ability to our model, implying a weak relationship between oil prices and NOK/USD exchange rate determination. 


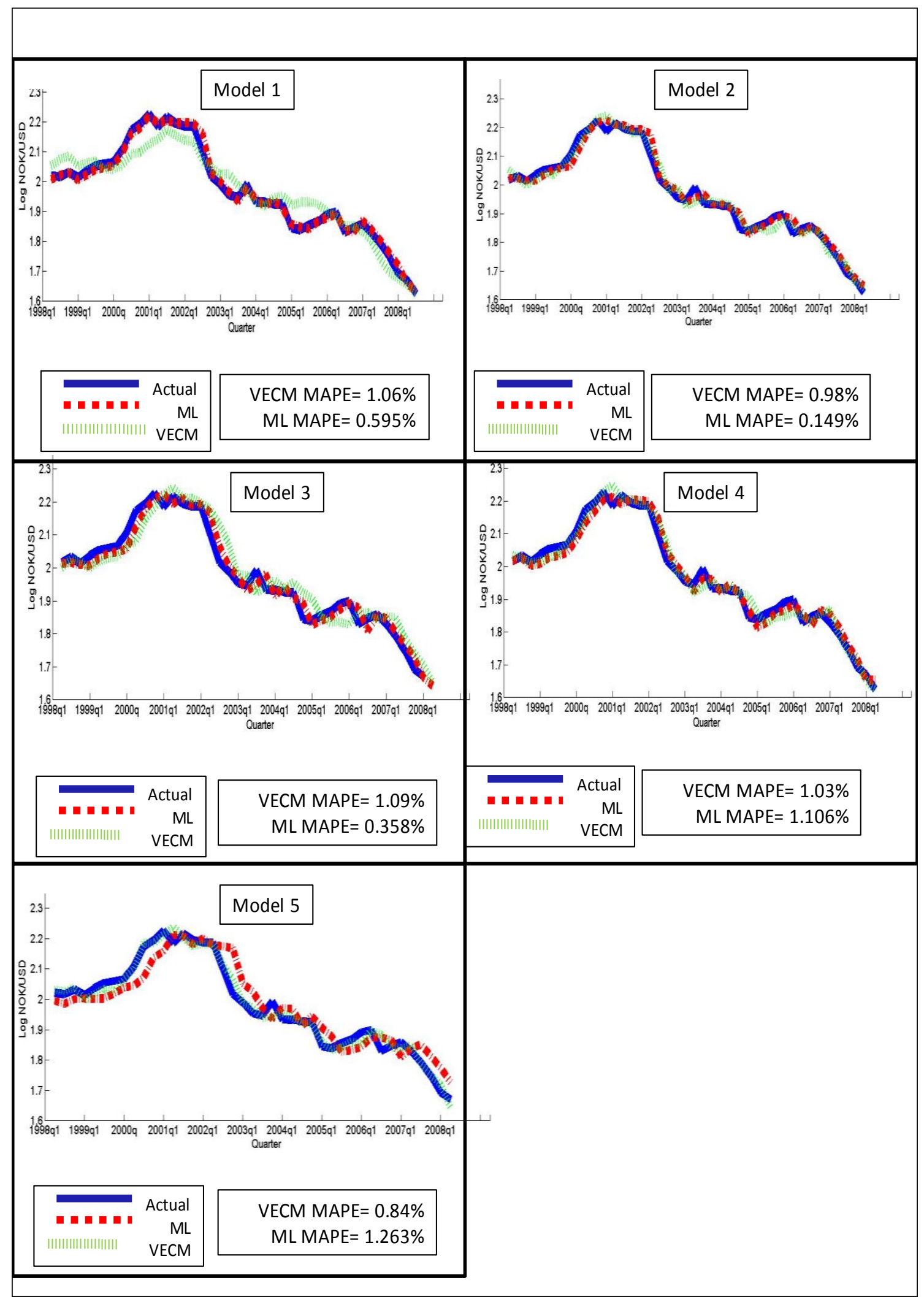

Figure 2: Comparison of VECM to SVR model forecasts. Model numbers refer to alternative inflation expectation estimations. 


\subsection{Dynamic Evolving Neuro-Fuzzy Inference System (DENFIS)}

The main disadvantage of the SVR methodology is the obscurity in inferring an analytical model structure. Consequently we are unable to measure the contribution of every independent variable on the final outcome (dependent variable) of the model. In order to bypass this drawback, we adopted the framework proposed by Farquad et al (2011) in extracting rules from a trained SVR model with the use of a DENFIS system.

The Dynamic Evolving Neuro-Fuzzy Inference System (DENFIS) proposed by A. Kasabov and Q. Song (2002) belongs to the broader category of Evolving Inference Systems. The basic notion behind DENFIS is to classify all observations into clusters and extract a fuzzy rule from each cluster. Then, treating globally all extracted fuzzy rules it develops a parametric linear function, linking the dependent to the independent variables and thus inferring a model structure that expresses the linear dependency between input and output variables.

With mathematical notation, for $\boldsymbol{x}_{\mathbf{1}}, \boldsymbol{x}_{2}, \ldots \ldots, \boldsymbol{x}_{\boldsymbol{n}}, i=1,2, \ldots, n$, independent input variables and $y$ the dependent (forecasted) one, the inference engine of DENFIS is composed by $m$ fuzzy rules where $m$ is smaller or equal to the data instances $n$. An extracted fuzzy rule $\mathrm{FR}_{\mathrm{m}}$ has the form

$$
\begin{aligned}
& F R_{m} \text { : if } \boldsymbol{x}_{\mathbf{1}} \text { is } R_{m 1} \text { and } \boldsymbol{x}_{\mathbf{2}} \text { is } R_{m 2} \text { and ....... and } \boldsymbol{x}_{\boldsymbol{n}} \text { is } R_{m n} \text { then } y \\
& =f_{m}\left(\boldsymbol{x}_{\mathbf{1}}, \boldsymbol{x}_{\mathbf{2}}, \ldots, \boldsymbol{x}_{\boldsymbol{n}}\right) \\
& \text { where } R_{i j}, \quad i=1,2, \ldots, m, j=1,2, \ldots, n
\end{aligned}
$$

In DENFIS, $R_{i j}$ are Gaussian Membership Functions (GMF), as noted in equation (13):

$$
R_{i j}(x)=\exp \left(\frac{-a(x-c)^{2}}{\sigma^{2}}\right)
$$

The 3 parameters of the system are: constant a, parameter $\mathrm{c}$ which represents the cluster center for the certain GMF and parameter $\sigma$ pointing GMFs (clusters) width.

The structure of a trained SVR model is defined by its SVs set and the distance of each vector from the so called "error-tolerance band". As a second step to the SVR model construction, the forecasted values of the most accurate SVR model are fed into a DENFIS for inferring its linear model representation. 


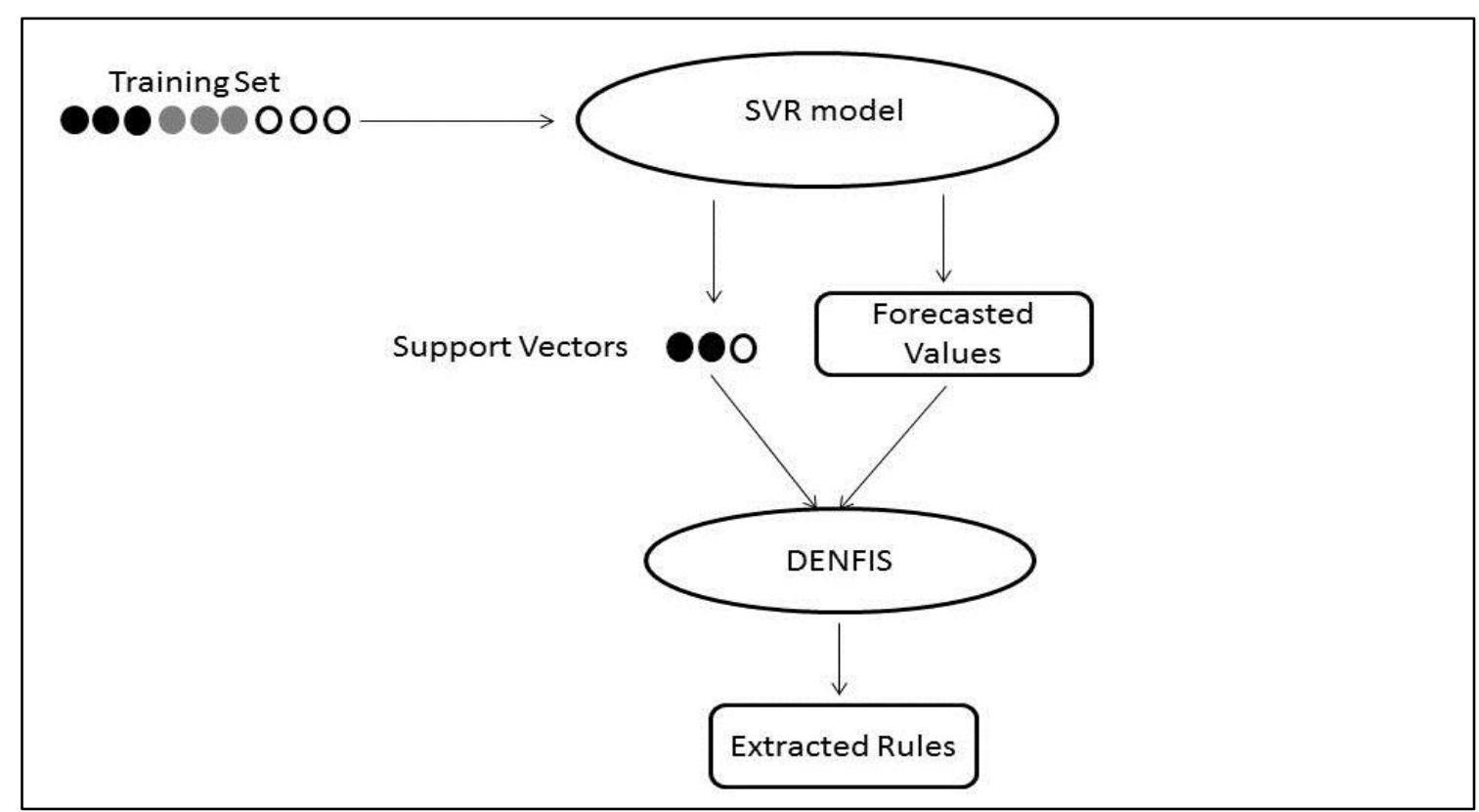

Figure 3: Overview of the experimental setup. After defining the SVR model with the lowest MAPE, Support Vectors and forecasted values are fed into a DENFIS for inferring the model structure.

DENFIS extracted 12 fuzzy rules reported in the Appendix A, approximating the forecasted values of the SVR model with the model structure:

$$
\begin{aligned}
s_{t+1}=0.36+ & 0.54 s_{t}+0.55\left(m-m^{*}\right)_{t}-0.12\left(y-y^{*}\right)_{t}+0.07\left(r-r^{*}\right)_{t}-0.80\left(\pi-\pi^{*}\right)_{t} \\
& -0.03 \text { oilp }_{t}
\end{aligned}
$$

From the coefficients of the SVR-DENFIS model in Equation (14) we observe that the signs of the coefficients for the money supply and output differentials are in line with all structural monetary exchange rate models described in the literature i.e. the flexible price, the sticky price and the interest rate differential monetary exchange rate model, although the value of the money supply differential coefficient is about half than expected (see Table 3).

\section{Table 3: Model Coefficients}

\begin{tabular}{lcccc}
\hline Coefficients & $m_{t}-m_{t}^{*}$ & $y_{t}-y_{t}^{*}$ & $r_{t}-r_{t}^{*}$ & $\pi_{t}-\pi_{t}^{*}$ \\
\hline Frenkel model & +1 & $<0$ & 0 & $>0$ \\
Bilson model & +1 & $<0$ & $>0$ & 0 \\
Dornbusch model & +1 & $<0$ & $<0$ & 0 \\
Frankel model & +1 & $<0$ & $<0$ & $>0$ \\
Best VECM & $>0$ & $<0$ & $>0$ & $>0$ \\
SVR-DENFIS & $>0$ & $<0$ & $>0$ & $<0$ \\
\hline \hline
\end{tabular}

Note: We denote the foreign counterpart with an asterisk

The sign of the coefficient for the interest rate differential is consistent only with the model proposed by the flexible price monetary model of Bilson (1978), stating that a rise in domestic interest rate today will cause a currency depreciation in the future. This 
finding coincides with earlier studies on Asian countries' currencies (Chinn, 2007a, b), the CAD/USD (Cushman, 2007) and the MXN/USD (Loria et al., 2009), gaining empirical verification. The inflation rate coefficient is in line with the flexible price model of Frenkel(1976) and the real interest rate differential model of Frankel (1979). The CPI-less energy inflation rate differential has a negative effect on the exchange rate, far more influential than all other variables of the model. Moreover, the positive coefficient of the first lag of the exchange rate implies persistence in exchange rate movements; i.e. ceteris paribus NOK exhibits a habit formation (Backus, Gregory and Telmer, 1993).

Focusing on the effect of oil price on the depended variable, we observe a small negative relationship between exchange rate evolution and oil price fluctuations, corroborating the result of Akram (2004) who detects a weak long-run relationship between NOK/USD rate and oil price fluctuations, for the time period 1 January 1996 to 12 August 1998. Thus, the example of Norway could be a viable solution for many small oil exporting economies, in order to limit the exposure of their exchange rates to oil price fluctuations. Overall, from the coefficients' sign of the SVR-DENFIS model we do not find evidence in favor of a specific monetary exchange rate model structure from the four models described in literature review. Nevertheless, the oil prices coefficient, along with the use of a CPI less energy approximation of inflation rate expectation indicates a weak effect of oil price fluctuations on NOK/USD determination.

\section{Conclusion}

In this paper we employed from the broader area of Machine Learning the Support Vector Regression methodology as an alternative to the standard VECM models. We empirically compared the forecasting ability of these methodologies on the basis of the general monetary exchange rate model used in Papadamou and Markopoulos (2012) for the NOK/USD exchange rate, using five alternative inflation expectation models. The results show that the Support Vector Regression model provides a more accurate forecast of the NOK/USD exchange rate as it is evidenced by the forecast evaluation criterion used, the MAPE. Moreover, the best forecasting model is the one employing an RBF kernel and a model that generates inflation expectations according to an AR(4) specification relieved of energy prices contribution on the price index, indicating weak exogenous oil effects on the exchange rate determination. Additionally, we derived the SVR model structure with the application of a DENFIS technique. The resulting model structure failed to identify a specific monetary exchange rate model from the ones proposed in literature according to variable coefficient signs, but revealed the crucial role of the inflation rate differential and thus monetary policy implications in determining the exchange rate. 


\section{Acknowledgments}

This research has been co-financed by the European Union (European Social Fund ESF) and Greek national funds through the Operational Program "Education and Lifelong Learning" of the National Strategic Reference Framework (NSRF) - Research Funding Program: THALES. Investing in knowledge society through the European Social Fund.

We would like to thank Dr. Papadamou for providing us with the original dataset of his own paper.

\section{References}

Abhyankar, Abhay \& Sarno, Lucio \& Valente, Giorgio (2005). Exchange rates and fundamentals: evidence on the economic value of predictability, Journal of International Economics, 66, 325-348.

Akram, Q. F. (2004). Oil prices and exchange rates: Norwegian evidence. The Econometrics Journal, 7, 476-504.

Backus, David, Allan Gregory, and Chris Telmer (1993). Accounting for Forward Rates in Markets for Foreign Currency. Journal of Finance, 48, 1887-1908.

Bilson, J. (1978). The monetary approach to the exchange rate-some empirical evidence. IMF Staff Papers. 25, 48-75.

Brandl Bernd and Leopold-Wildburger Ulrike (2009), Increasing the Fitness of Fundamental, Exchange Organizational Behavior Teaching Journal, 4, 779 - 798.

Cheung,Y.-W., Chinn M. and Pascual A.G. (2005) Empirical Exchange Rate Models of the Nineties: Are any Fit to Survive?, Journal of International Money and Finance, 24, 1150-75.

Chin, L., Azali, M., \& Matthews, G. (2007a). The monetary approach to exchange rate determination for Malaysia. Applied Financial Economic Letters, 3, 91-94.

Chin, L., Azali, M., Yusop, Z. B., \& Yusoff, M. B. (2007b). The monetary model of exchange rate: evidence from the Philippines. Applied Economic Letters, 14, 993997.

Cushman, D. (2007). A portfolio balance approach to the Canadian-U.S. exchange rate. Review of Financial Economics, 16, 305-320.

De Grauwe, P. (1996).International money: Postwar-trends and theories, New York: Oxford: Oxford University Press, 146-147.

Della Corte, Pasquale \& Sarno, Lucio \& Tsiakas, Ilias (2011). Spot and forward volatility in foreign exchange, Journal of Financial Economics, 100, 496-513.

Dornbusch, R. (1976). Expectations and exchange rate dynamics. Journal of Political Economy, 84, 1161-1176

Engel C. and West K. (2005), Exchange Rates and Fundamentals, Journal of Political Economy, 113, 485-517. 
Farquad M., Ravi V. and Bapi Raju S, (2010), Support vector regression based hybrid rule extraction methods for forecasting, Expert Systems with Applications: An International Journal, 37, 5577-5589.

Frankel, J. A. (1979). On the mark: a theory of floating exchange rates based on real interest differentials. American Economic Review, 69, 610-622.

Frenkel, J. A. (1976). A monetary approach to the exchange rate: doctrinal aspects and empirical evidence. The Scandinavian Journal of Economics, 78, 200-224

Frenkel, M., \& Koske, I. (2004). How well can monetary factors explain the exchange rate of the euro? Atlantic Economic Journal, 32, 232-243.

Ince $\mathrm{H}$ and Trafalis T,(2006), A hybrid model for exchange rate prediction, Decision Support Systems, 42, 1054-1062.

Johansen, S., \& Juselius, K. (1990). Maximum likelihood estimation and inferences on cointegration-with applications to the demand for money. Oxford Bulletin of Economics and Statistics, 52, 169-210.

Kasabov N.K. and Song Qun (2002), Dynamic evolving neuro-fuzzy inference system (DENFIS), IEEE Transactions on Fuzzy Systems, 10, 144.

Kloster, A. (2000). Estimating and interpreting interest rate expectations. Norges Economic Bulletin, LXXI, 85-94.

Loria, E., Sanchez, A., \& Salgado, U. (2009). New evidence on the monetary approach of exchange rate determination in Mexico 1994-2007: a cointegrated SVAR model. Journal of International Money and Finance, 29, 540-554.

Miyakoshi, T. (2000). The monetary approach to the exchange rate: empirical observations from Korea. Applied Economics Letters, 7, 791-794.

Papadamou S. and Markopoulos T. (2012), The Monetary Approach to the Exchange Rate Determination for a "Petrocurrency": The Case for Norwegian Krone, International Advances in Economic Research, vol. 18, pp. 299-314.

Rime D., Sarno L. and Sojli E. (2010), Exchange rate forecasting, order flow and macroeconomic information, Journal of International Economics, vol. 80, pp. 7288 .

Scholkopf B. and Smola A. J. (2002). Learning with Kernels. MIT Press. US.

Schwarz, Gideon E. (1978). Estimating the dimension of a model. Annals of Statistics, vol. 6 (2), pp. 461-464.

Svensson, L. E. O. (1994).Estimating and interpreting forward rates: Sweden $1992-$ 1994. No. 94/114 Working Paper Series, International Monetary Fund.

Vapnik V. (1992), The Nature of Statistical Learning Theory. Springer-Verlag, New York. 


\section{$\underline{\text { Appendix A }}$}

\begin{tabular}{|c|c|c|c|c|c|c|}
\hline \multicolumn{7}{|c|}{ Table A-1: First order TSK rules extracted by DENFIS } \\
\hline \multicolumn{2}{|c|}{ Rule } & \multicolumn{3}{|c|}{ Antecedent part } & \multicolumn{2}{|c|}{ Model Specification } \\
\hline \multirow[t]{7}{*}{1} & $\mathrm{i}$ & if $\mathrm{X} 1$ is $(0.70$ & 0.8 & $310.92)$ & $\mathrm{Y}=$ & $=0.17$ \\
\hline & & $\mathrm{X} 2$ is $(0.53$ & 30.6 & $4 \quad 0.75)$ & & $+0.11 * X 1$ \\
\hline & & $\mathrm{X} 3$ is $(0.37$ & $7 \quad 0.4 \varepsilon$ & $80.59)$ & & $+0.42 * \times 2$ \\
\hline & & $\mathrm{X} 4$ is $(0.23$ & $3 \quad 0.32$ & $4 \quad 0.45)$ & & $+0.49 * \times 3$ \\
\hline & & $\mathrm{X} 5$ is $(0.39$ & 90.50 & $0 \quad 0.61)$ & & $-0.41 * x 4$ \\
\hline & & $\mathrm{X} 6$ is $(0.70$ & 0.8 & $10.92)$ & & $+0.03 * \times 5$ \\
\hline & & & & & & $+0.04 * \times 6$ \\
\hline \multirow[t]{7}{*}{2} & if & $\mathrm{X} 1$ is $(0.53$ & 0.64 & $0.75)$ & $Y=$ & $=0.88$ \\
\hline & & $\mathrm{X} 2$ is $(0.21$ & $1 \quad 0.32$ & $20.43)$ & & $-0.17 * x 1$ \\
\hline & & $\mathrm{X} 3$ is $(0.56$ & $5 \quad 0.67$ & $7 \quad 0.78)$ & & $+0.09 * \times 2$ \\
\hline & & $\mathrm{X} 4$ is $(0.18$ & $8 \quad 0.25$ & $90.40)$ & & $+0.23 * \times 3$ \\
\hline & & $\mathrm{X} 5$ is $(0.36$ & $5 \quad 0.47$ & $\begin{array}{ll}7 & 0.58)\end{array}$ & & $-0.50 * x 4$ \\
\hline & & $\mathrm{X} 6$ is $(0.56$ & 50.67 & $\left(\begin{array}{ll}7 & 0.78\end{array}\right)$ & & $-0.80 * x 5$ \\
\hline & & & & & & $+0.38 * \times 6$ \\
\hline \multirow[t]{7}{*}{3} & if & $\mathrm{X} 1$ is $(0.46$ & 0.57 & $0.68)$ & $Y=$ & $=0.24$ \\
\hline & & $\mathrm{X} 2$ is $(0.36$ & $5 \quad 0.47$ & $\begin{array}{ll}7 & 0.58)\end{array}$ & & $+0.19 * \mathrm{x} 1$ \\
\hline & & $\mathrm{X} 3$ is $(0.21$ & $1 \quad 0.33$ & $30.44)$ & & $-0.09 * x 2$ \\
\hline & & $\mathrm{X} 4$ is $(0.28$ & $8 \quad 0.35$ & $90.50)$ & & $+0.45 * \times 3$ \\
\hline & & $\mathrm{X} 5$ is $(0.49$ & $\begin{array}{ll}9 & 0.60\end{array}$ & $0 \quad 0.71)$ & & $+0.47 * X 4$ \\
\hline & & $\mathrm{X} 6$ is $(0.51$ & 10.62 & $20.73)$ & & $-0.48 * x 5$ \\
\hline & & & & & & $+0.25 * \times 6$ \\
\hline \multirow[t]{7}{*}{4} & if & $\mathrm{X} 1$ is $(0.48$ & 0.59 & $0.70)$ & $Y=$ & $=-1.49$ \\
\hline & & $\mathrm{X} 2$ is $(0.56$ & $5 \quad 0.67$ & $7 \quad 0.78)$ & & $+1.03 * X 1$ \\
\hline & & $\mathrm{X} 3$ is $(0.52$ & 20.63 & $30.74)$ & & $+0.85 * \times 2$ \\
\hline & & $\mathrm{X} 4$ is $(0.67$ & $7 \quad 0.7 \varepsilon$ & $8 \quad 0.89)$ & & $+1.10 * x 3$ \\
\hline & & $\mathrm{X} 5$ is $(0.63$ & $3 \quad 0.74$ & $\left.\begin{array}{ll}4 & 0.85\end{array}\right)$ & & $+0.10 * X 4$ \\
\hline & & $\mathrm{X} 6$ is $(0.23$ & $3 \quad 0.3$ & $4 \quad 0.45)$ & & $-0.03 * x 5$ \\
\hline & & & & & & $+0.54 * \times 6$ \\
\hline \multirow[t]{7}{*}{5} & $\mathrm{i}$ & if $\mathrm{X} 1$ is $(0.6$ & $7 \quad 0.7 \varepsilon$ & $80.89)$ & $Y=$ & $=-1.03$ \\
\hline & & $\mathrm{X} 2$ is $(0.67$ & $7 \quad 0.7 \varepsilon$ & $8 \quad 0.89)$ & & $+1.22 * X 1$ \\
\hline & & $\mathrm{X} 3$ is $(0.34$ & $4 \quad 0.45$ & $5 \quad 0.56)$ & & $+0.57 * \times 2$ \\
\hline & & $\mathrm{X} 4$ is $(0.09$ & $\begin{array}{ll}9 & 0.2 C\end{array}$ & $\left(\begin{array}{ll}0 & 0.31\end{array}\right)$ & & $+1.07 * X 3$ \\
\hline & & $\mathrm{X} 5$ is $(0.63$ & 30.7 & $4 \quad 0.85)$ & & $-0.03 * x 4$ \\
\hline & & $\mathrm{X} 6$ is $(0.58$ & 80.65 & $90.80)$ & & $+0.22 * \times 5$ \\
\hline & & & & & & $-0.28 * x 6$ \\
\hline \multirow[t]{6}{*}{6} & if & $\mathrm{X} 1$ is $(0.36$ & 0.47 & $0.58)$ & $Y=$ & $=1.37$ \\
\hline & & $\mathrm{X} 2$ is $(0.30$ & 0.4 & $10.52)$ & & $-0.17 * x 1$ \\
\hline & & $\mathrm{X} 3$ is $(0.57$ & $7 \quad 0.6 \varepsilon$ & $80.79)$ & & $-0.47 * x 2$ \\
\hline & & $\mathrm{X} 4$ is $(0.26$ & $\begin{array}{ll}5 & 0.37\end{array}$ & $\left.\begin{array}{ll}7 & 0.48\end{array}\right)$ & & $+0.19 * x 3$ \\
\hline & & $\mathrm{X} 5$ is $(0.10$ & 0.21 & $10.32)$ & & $-0.71 * x 4$ \\
\hline & & $\mathrm{X} 6$ is $(0.40$ & 0.5 & $10.62)$ & & $-0.77 * x 5$ \\
\hline
\end{tabular}




\begin{tabular}{|c|c|c|c|c|c|c|}
\hline & & & & & & $-0.05 * x 6$ \\
\hline 7 & if & $\begin{array}{l}X 1 \text { is }(0.14 \\
X 2 \text { is }(0.61 \\
X 3 \text { is }(0.59 \\
X 4 \text { is }(0.30 \\
X 5 \text { is }(0.49 \\
X 6 \text { is }(0.66\end{array}$ & $\begin{array}{l}0.25 \\
0.72 \\
0.70 \\
0.41 \\
0.60 \\
0.77\end{array}$ & $\begin{array}{l}0.36) \\
0.83) \\
0.81) \\
0.52) \\
0.71) \\
0.88)\end{array}$ & $Y=$ & $\begin{array}{l}1.11 \\
\quad+0.88 * X 1 \\
-0.51 * X 2 \\
+0.32 * X 3 \\
-1.01 * X 4 \\
+0.02 * X 5 \\
-0.60 * X 6\end{array}$ \\
\hline 8 & if & $\begin{array}{l}X 1 \text { is }(0.17 \\
X 2 \text { is }(0.05 \\
X 3 \text { is }(0.44 \\
X 4 \text { is }(0.23 \\
X 5 \text { is }(0.44 \\
X 6 \text { is }(0.61\end{array}$ & $\begin{array}{l}0.28 \\
0.16 \\
0.55 \\
0.34 \\
0.55 \\
0.72\end{array}$ & $\begin{array}{l}0.39) \\
0.27) \\
0.66) \\
0.45) \\
0.66) \\
0.83)\end{array}$ & $Y=$ & $\begin{array}{l}1.39 \\
\quad+0.11 * X 1 \\
-0.50 * x 2 \\
+0.24 * X 3 \\
-0.83 * X 4 \\
-1.04 * X 5 \\
-0.12 * X 6\end{array}$ \\
\hline 9 & if & $\begin{array}{l}X 1 \text { is }(0.46 \\
X 2 \text { is }(0.42 \\
X 3 \text { is }(0.33 \\
X 4 \text { is }(0.23 \\
X 5 \text { is }(0.48 \\
X 6 \text { is }(0.22\end{array}$ & $\begin{array}{l}0.57 \\
0.53 \\
0.44 \\
0.34 \\
0.59 \\
0.33\end{array}$ & $\begin{array}{l}0.68) \\
0.64) \\
0.55) \\
0.45) \\
0.70) \\
0.44)\end{array}$ & $Y=$ & $\begin{array}{r}-0.19 \\
-0.13 * \times 1 \\
+0.50 * x 2 \\
+0.86 * x 3 \\
-0.16 * x 4 \\
-0.11 * \times 5 \\
+0.45 * \times 6\end{array}$ \\
\hline 10 & if & $\begin{array}{l}X 1 \text { is }(0.49 \\
X 2 \text { is }(0.52 \\
X 3 \text { is }(0.63 \\
X 4 \text { is }(0.09 \\
X 5 \text { is }(0.53 \\
X 6 \text { is }(0.14\end{array}$ & $\begin{array}{l}0.60 \\
0.63 \\
0.74 \\
0.20 \\
0.64 \\
0.25\end{array}$ & $\begin{array}{l}0.71) \\
0.74) \\
0.85) \\
0.31) \\
0.75) \\
0.36)\end{array}$ & $Y=$ & $\begin{array}{r}-0.25 \\
\quad+0.52 * X 1 \\
+0.74 * X 2 \\
+0.59 * X 3 \\
-0.91 * X 4 \\
-0.29 * X 5 \\
+0.31 * X 6\end{array}$ \\
\hline 11 & if & $\begin{array}{l}X 1 \text { is }(0.39 \\
X 2 \text { is }(0.75 \\
X 3 \text { is }(0.53 \\
X 4 \text { is }(0.18 \\
X 5 \text { is }(0.09 \\
X 6 \text { is }(0.80\end{array}$ & $\begin{array}{l}0.50 \\
0.86 \\
0.64 \\
0.29 \\
0.20 \\
0.91\end{array}$ & $\begin{array}{l}0.61) \\
0.97) \\
0.75) \\
0.40) \\
0.31) \\
1.02)\end{array}$ & $Y=$ & $\begin{array}{l}1.75 \\
\quad+0.45 * X 1 \\
\quad-0.77 * X 2 \\
+0.72 * X 3 \\
\quad-1.57 * X 4 \\
+0.34 * X 5 \\
\quad-1.22 * X 6\end{array}$ \\
\hline 12 & if & $\begin{array}{l}X 1 \text { is }(0.11 \\
X 2 \text { is }(0.71 \\
X 3 \text { is }(0.61 \\
X 4 \text { is }(0.32 \\
X 5 \text { is }(0.70 \\
X 6 \text { is }(0.31\end{array}$ & $\begin{array}{l}0.22 \\
0.82 \\
0.72 \\
0.43 \\
0.81 \\
0.42\end{array}$ & $\begin{array}{l}0.33) \\
0.93) \\
0.83) \\
0.54) \\
0.92) \\
0.53)\end{array}$ & $Y=$ & $\begin{array}{l}0.36 \\
\quad+0.54 * \times 1 \\
+0.55 * \times 2 \\
-0.12 * \times 3 \\
+0.07 * \times 4 \\
-0.03 * \times 5 \\
-0.80 * \times 6\end{array}$ \\
\hline
\end{tabular}

